\title{
CP. 02. Modeling a modulatory role in intermodular communication
}

\author{
FILHO, J.D. ${ }^{a}$, DINIZ, N.V.A. ${ }^{b}$
}

aDepartamento de Fisiologia e Farmacologia - Faculdade de Medicina, Universidade Federal do Ceará - UFC, Fortaleza, Brazil

bBolsista de IC - FUNCAP, Faculdade de Medicina, Universidade de Fortaleza - UNIFOR, Fortaleza, Brazil

Introduction: In recent reviews on neurosciences, computational modeling has emerged as an extremely powerful tool. Importantly, there is an appeal for new models (with required biological plausibility) whose discussion and functionality is supposed to help as a bridge in the communication gap between both modeler and empiricist communities. Objectives: In the present work, our aim is to show the functionality of a connectionist modular model. It stands as an effort to overcome model limitations with regard to experimental validation. Methods: We present a connectionist model, in the range of network and neuron levels, designed to represent modularity as an explicit component in the network architecture. Beyond special connections in the architecture of the network, the required specifications in the project imply in a particular definition for the activation function of neurons inside modules. This is intended to incorporate additional flexibility to the network operation, as well as to represent neuronal segments with specific physiological characteristics in the intermodular communication. Furthermore, a central feature in this architecture is the role played by one of the modules, whose interference is critical for the computing properties of the whole modular assembly. This module is thus defined as a special one, with a modulatory character. Results: As a result of the modulatory module relationships, it was showed that the network operation was done in terms of choices among some available capabilities, which were previously formulated for the integrated modules. Moreover, there was a clear difference in trends when comparing a lesioned version of the model with an intact version. Despite these results, the model presented limitation points in the modules relationships and in the activation functions. Conclusions: Model's limitations are in the sense that it lacks a better defined set of parameters and functions. This caused further consequences in our repeated trials in order to make feasible integration with experimental tests.

FILHO, J.D.; DINIZ, N.V.A. 2013. Modeling a modulatory role in intermodular communication, p.11. In: Oriá, Reinaldo Barreto; Andrade, Geanne Matos de; Bruin, Veralice Meireles S. de. I International Symposium in Neuroscience Meeting [Blucher Neuroscience Proceedings n.1 v.1]. São Paulo: Blucher, 2014 http://dx.doi.org/10.5151/isnm-sine6

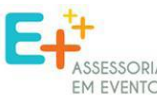

